\title{
Learning Sustainable Design through Service
}

\author{
Karim Al-Khafaji \\ PhD Student, Department of Biological Sciences \\ Stanford University \\ Stanford, CA 95305 \\ Khafaji@Stanford.edu \\ Margaret Catherine Morse \\ PhD Student, Department of Civil and Environmental Engineering \\ Stanford University \\ Stanford, CA 95305 \\ Morse@Stanford.edu
}

\begin{abstract}
Environmental sustainability and sustainable development principles are vital topics that engineering education has largely failed to address. Service-learning, which integrates social service into an academic setting, is an emerging tool that can be leveraged to teach sustainable design to future engineers. We present a model of using servicelearning to teach sustainable design based on the experiences of the Stanford chapter of Engineers for a Sustainable World. The model involves the identification of projects and partner organizations, a student led, project-based design course, and internships coordinated with partner organizations. The model has been very successful, although limitations and challenges exist. These are discussed along with future directions for expanding the model.
\end{abstract}

Index Terms - Development, engineering education, service learning, sustainability.

\section{INTRODUCTION}

Teaching environmental sustainability and sustainable design principles is one of the most pressing topics in engineering education in the $21^{\text {st }}$ century. The United Nations reaffirmed its commitment to sustainable development in its Millennium Development Goals ${ }^{1}$, and both the 1992 Earth Summit ${ }^{2}$ and the World Summit on Sustainable Development ${ }^{3}$ highlighted the central role that education must play to realize the goal of sustainable development. Has engineering education risen to meet this challenge? A recent international survey of engineering students found that, while most students recognized the importance of sustainable development, there were widespread and startling knowledge gaps about many core aspects of sustainable development ${ }^{4}$. Particularly interesting was that U.S.-based students had the lowest average level of knowledge about sustainable development, although as the authors noted, this finding should be interpreted with caution due to low response rates from U.S. universities ${ }^{5}$. A separate inquiry similarly found that educational institutions in the U.K. were inadequately training engineers in sustainable development ${ }^{6}$ and that progress on incorporating sustainability into engineering curricula has been quite modest ${ }^{7}$. Clearly there is a pressing need to better incorporate sustainability into engineering curricula, and also a simultaneous need for better tools to teach sustainable design.

In the last decade there has been rising interest in service learning in engineering, as inferred from the increasing number of articles published on the topic (see Figure 1); however, the 
objectives and outcomes of service learning initiatives are extremely diverse, including: increasing student recruitment and retention ${ }^{8,9}$, teaching engineering ethics ${ }^{10}$, encouraging social awareness $^{11}$, introducing engineering to first-year students ${ }^{12,13,14,15}$, increasing appreciation of the engineering profession ${ }^{16}$, and providing a quality design experience that emphasizes both technical and non-technical skills, such as communication and working in teams ${ }^{17,18,19}$. There are examples of service learning to teach sustainable design principles (e.g., ${ }^{20,21,22,23}$ ) but the field is still in its infancy ${ }^{24}, 25$ with much room for the development and discussion of methodologies to effectively leverage service learning to meet the challenge of educating the next generation of engineers about sustainability.

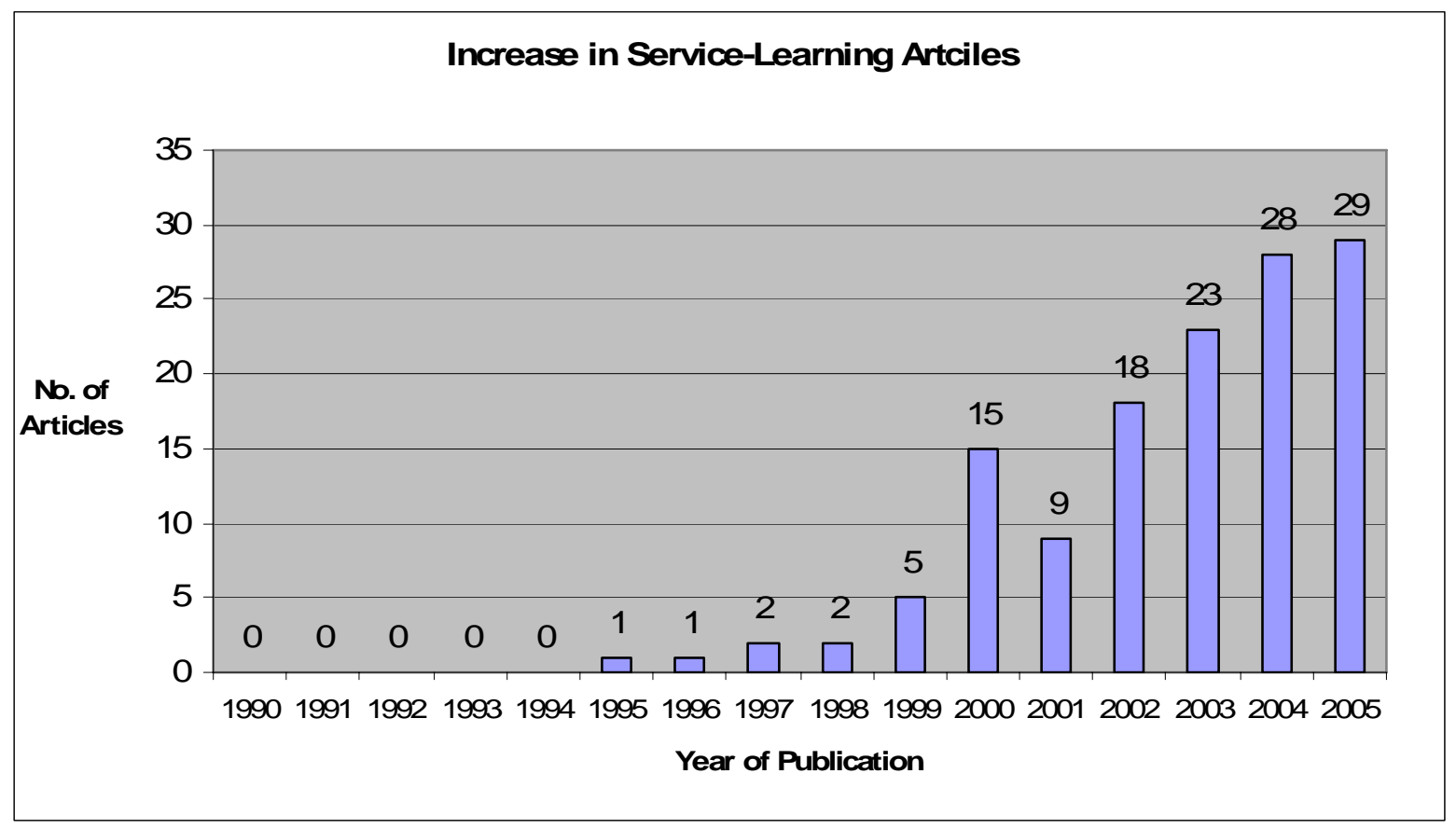

FIGURE 1

SERVICE-LEARNING ARTICLES BY YEAR ${ }^{26}$

In this paper we present a potentially replicable model for using service projects to teach sustainable design principles; the model is based on the experiences of the Stanford chapter of Engineers for a Sustainable World (ESW-Stanford), an international non-profit organization dedicated to promoting sustainable development ${ }^{27}$. The ESW-Stanford approach has evolved after several iterations of coordinating a course titled "Design for a Sustainable World," which ESW-Stanford introduced via a student initiative in response to a lack of sustainable development training in the engineering curriculum. The model is composed of three interrelated elements: 1) project selection and identification of partner organizations, 2) the "Design for a Sustainable World" course, and 3) student internships to implement (and extend) the design developed during the course. In the next several sections of this paper we describe the various elements of the model in greater detail, with specific reference to a recent project in the Andaman Islands focusing on rebuilding after the December 26, 2004 earthquake and tsunami. Where appropriate, we draw parallels between our model and other examples of service learning 
programs available in the literature. Following the detailed description of the model elements, we describe some challenges to the model and conclude by discussing our vision for the continuing evolution of ESW-Stanford's efforts to promote sustainable design education.

\section{MODEL DESCRIPTION}

\section{Project Selection and Identification of Partners}

The identification of potential projects is a flexible, organic process. Although there is an officer of ESW-Stanford dedicated to coordinating projects, specific opportunities are identified in a variety of ways, including: potential collaborators approaching us directly for help on specific design challenges, a student identifying a potential need and project opportunity, or a past collaborator mentioning the need for future work. As an example, after the humanitarian crisis caused by the December 26, 2004 earthquake and tsunami in the Indian Ocean, an informal group of students began meeting to discuss ways that the skills, expertise, and resources of ESWStanford could be used to assist in sustainable redevelopment efforts. The group evolved into an ad hoc committee screening potential projects according to various criteria including: the extent of the damage in the region, whether the amount of aid being received was insufficient, the likely safety of field personnel, and the availability of suitable partner organizations. This process resulted in the selection of the Andaman Islands, a Union Territory of India but geographically a northern extension of the Indonesian archipelago, as a project location. The scope of the project, to design a rainwater collection and treatment system for residents of intermediate shelters, as well as provide design recommendations to improve the livability and environmental sustainability of permanent housing, was defined in collaboration with an Indian development group already working in the Andaman Islands.

Similar to other models of service learning (e.g., EPICS described $\mathrm{in}^{28}$ ) local partner organizations are an integral part of defining the scope and detailed objectives of any project. Logistical challenges such as "geographic, cultural, and language barriers 29 ", often necessitate the formation of collaborations with local groups to adequately evaluate the needs of the community as well as identify any legal requirements (e.g. requisite visas and permits). Local partners are invaluable at assessing the cultural appropriateness of design projects, a key determinant of success, and they are typically a source of data, contacts, and information about available materials and local practices. Partner organizations in many respects are the "client" and learning how to interact with them during the design and implementation process is also an important educational outcome ${ }^{30}$, with direct application to the professional practice of engineering.

Given the importance of local partner organizations, it is ESW-Stanford's policy that the potential collaborators be researched thoroughly to ensure compatibility. This includes evaluating their mission statement, investigating how they were originally founded, researching outcomes of past projects and previous partnerships, as well as contacting past collaborators if possible. Also important is their resources and commitment to the current project.

Identifying projects and partners is an ongoing process complicated by the need to make selections with sufficient lead-time to plan the design course and implementation components. Both the design course and the implementation are costly endeavors that require considerable fundraising from both university and external sources; however, a specific project is generally a prerequisite for grant proposals and funding solicitations. Similarly, time is needed to conduct preliminary research, recruit a teaching assistant (TA) for the design course, prepare relevant 
course materials, arrange guest lectures, investigate logistical hurdles (like vaccination requirements), etc. The demands of identifying projects and associated preparatory work led to the creation of a leadership position within ESW-Stanford dedicated to coordinating projects, the Project Coordinator. In addition, the help of other ESW-Stanford officers and volunteers is required.

\section{Design Course}

The service project serves as the focal point of a student led course, titled "Design for a Sustainable World.” The course seeks to:

- Develop students' iterative design skills, project management and partnership-building abilities, sustainability awareness, cultural sensitivity, empathy, and desire to use technical skills to promote peace and human development.

- Help developing communities ensure individuals' human rights via sustainable, culturally appropriate, technology-based solutions.

- Increase Stanford University's stewardship of global sustainability.

The course is typically offered in two academic quarters per year. It is listed both as an undergraduate/graduate course through the Department of Civil and Environmental Engineering and is open to students of all majors; the course is currently offered Satisfactory/No Credit and students may receive 1-5 quarter hours of elective credit. The flexibility in the number of quarter hours is primarily provided to accommodate graduate students, who typically have strict limitations on the number of credits taken per quarter dictated by the conditions of their stipend or research schedule. Students typically enroll for 3 units; students receiving less credit are still required to perform an equivalent amount of work, while students receiving more credit must individually arrange to submit additional independent work. It is expected that the students will be present at all classes, that they will complete weekly homework, midterms and final presentations, that they will be thoughtful and thorough with research and critique, and that they will maintain meticulous communication and documentation for the future of the project.

Prior to enrolling in the course, prospective students must go through a rigorous application process. This guarantees that only serious, motivated students take the course and helps ensure that the students selected are willing to put in the time and effort required for a project-based design course. Furthermore, the brevity of an academic quarter (10 weeks) and the project and team-based nature of the course necessitate that the roster is fixed from the outset without the usual student turnover experienced in other courses. The application process can also be used to balance the mix of skill sets and personality styles in the course, although motivation and enthusiasm are the primary factors considered.

The course is student led, and while the teaching assistant (TA) typically has training and experience relevant to the project, he/she is not expected to be an "expert" on specific topics, but rather is a facilitator of the learning process. The TA is responsible for:

- Creating the syllabus and general outline for the class

- Selecting appropriate readings as necessary

- Preparing, collecting, and grading all homework assignments

- Maintaining and organizing all submittals and student reports

- Facilitating team formation and distribution of sub-projects

- Coordinating communication with the project partner 
- Scheduling guest lectures (ESW-Stanford will help with contacts whenever needed, but it is the role of the TA to decide what sort of lecturer is required)

- Reviewing class applications, if required by the Project Coordinator

Originally the TA was a volunteer position, but in recent quarters the TA has been paid by the Department of Civil and Environmental Engineering. Given the responsibilities of the TA and the amount of time required, we believe that the compensation is merited and engenders a sense of ownership of projects that has resulted in a more consistent and higher-quality learning experience for the students.

Technical content related to the project is taught by guest lecturers, chosen from university faculty and staff as well as industry professionals. Many of the guest lecturers also agree to be consultants for the project if needed. In addition to technical subjects, the TA also arranges speakers from "softer" fields that are more broadly related to projects, organizations, and interpersonal relations. These lectures may include issues such as cultural sensitivity, teamwork, negotiation, and personality. Early in the quarter, the lectures are supplemented by homework assignments and readings that are often used to provide a greater breadth of exposure to sustainable design topics than the somewhat narrower focus of the current project.

As a design class, much of the learning is accomplished through the research and iterative design process performed by the students. Typically the project is broken into sub-projects accomplished by teams of students. The teams meet throughout the quarter to receive feedback and direction from the TA. Although the TA or Project Coordinator is the conduit for communication with the partner organization, in order to maintain continuity and limit the volume of queries, the partner organization is active in providing information and critique of preliminary designs. The teams are required to prepare a midterm presentation on their subproject, where professors, industry professionals, ESW-Stanford officers and members from the partner organization critique the design and provide input and advice. A final presentation and technical report are also required. The general public is invited to the final presentations and there is a question and answer session, allowing the students to hone their ability to communicate technical information to non-technical audiences.

In the case of the Andaman Islands project, guest lectures were arranged on "green" building methods, cultural aspects of community design, and decentralized water treatment, among others. An example homework assignment was to investigate a particular water supply or treatment technique appropriate for developing communities and present the findings to the class. For the final design, teams prepared scale models and prototypes of rainwater harvesting and filtration systems that could be constructed with inexpensive, locally available materials. Similarly, the team focused on the permanent housing design did a thorough analysis of alternative construction materials and provided detailed recommendations ranging from the square footage to provide per individual to the necessity of adequate foundations.

\section{Implementation}

A key feature of the ESW-Stanford model is that it links the work from the design course with actual experience in the field via internships offered during the summer quarter. The opportunity to see designs come to fruition in the real world is rarely afforded in academic contexts, making the internship experience invaluable for participants. The internships are open to all students, although strong preference is given to students who completed the "Design for a Sustainable World" course. Thus the internship is not mandatory for students enrolled in the design course, 
nor is the course a strict prerequisite for the internship. This allows students who are interested in sustainable design to take the course and make valuable contributions to an actual project, even if they are unable to commit to the internship, which can be both physically and psychologically demanding. Similarly, students with significant academic or professional experience can participate in the internship without taking on the academic burden of the course. In order to be accepted for the internship, students must complete an application and interview, commit to at least six weeks at the project location, and participate in fundraising efforts.

The internships are overseen and administratively supported by the partner organization. The students report to the local partner organization office where they are integrated into a team of development professionals working on the project that served as the focus of the design course. The primary goal of the internship is to provide continuing design services for the focal project as it is implemented; however, additional projects and engineering responsibilities may also be undertaken during the internships. On the Andaman Islands project, interns refined and modified the rainwater harvesting design developed during the course, but also performed an in-depth assessment of the current conditions and a needs analysis for the temporary shelter community. The assessment was multi-faceted involving disparate techniques ranging from topographical surveying to extensive community interviews on water-handling practices and attitudes. The initial assessment resulted in a ranked list of necessary or desirable improvements to increase the livability of the community. Chief among the recommended projects were improved drainage/sanitation and a community center. ESW-Stanford interns took the lead on these projects and developed detailed designs to improve the drainage of the site (Figure 2) in order to reduce exposure to waterborne diseases and disease vectors like mosquitoes. The design plans were submitted to the local government agency who implemented them without major revisions. Similarly, ESW-Stanford interns created design plans for a community center (Figure 3) that was subsequently built by our local partner.

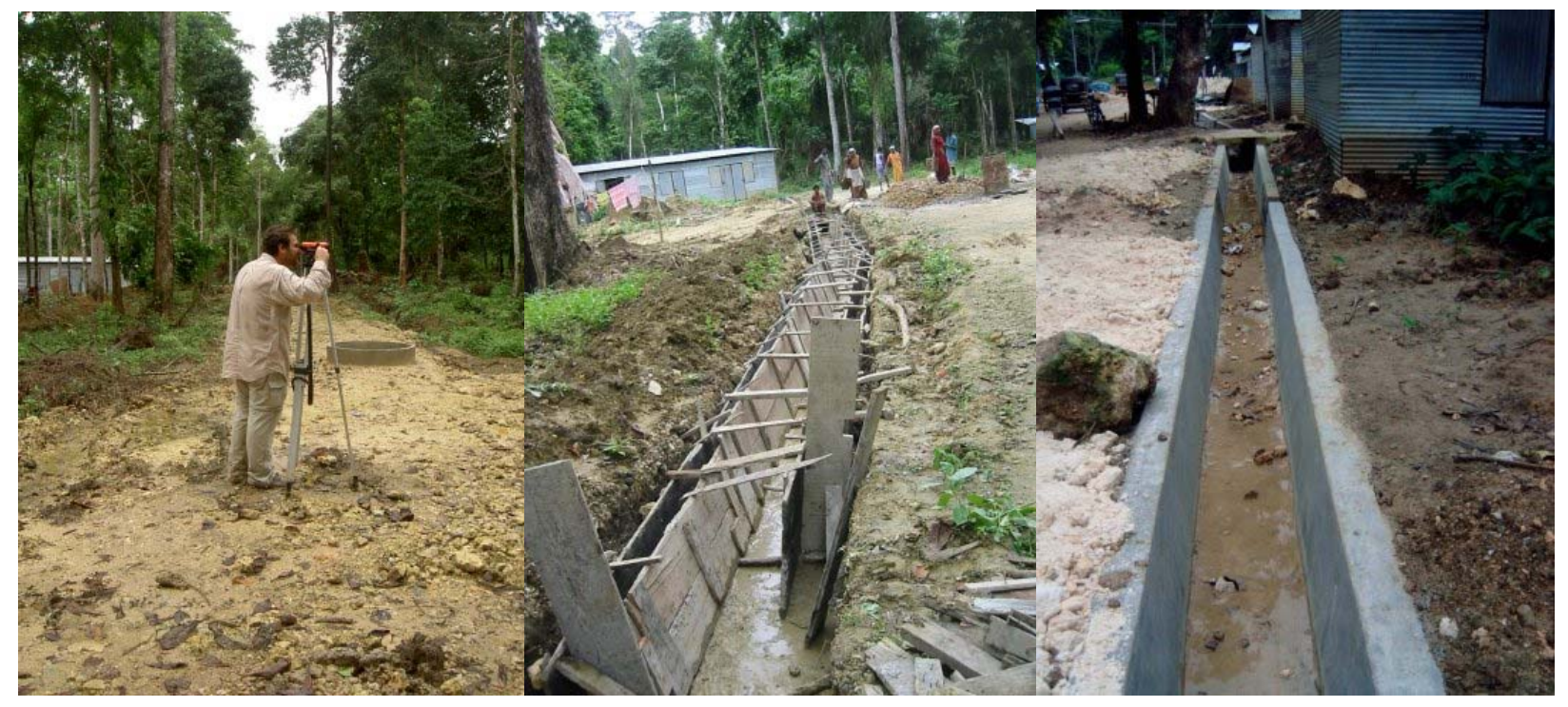

FIGURE 2

SURVEYING AND CONSTRUCTION OF SITE DRAINAGE IN HUTBAY, LiTTLE ANDAMAN ISLAND 


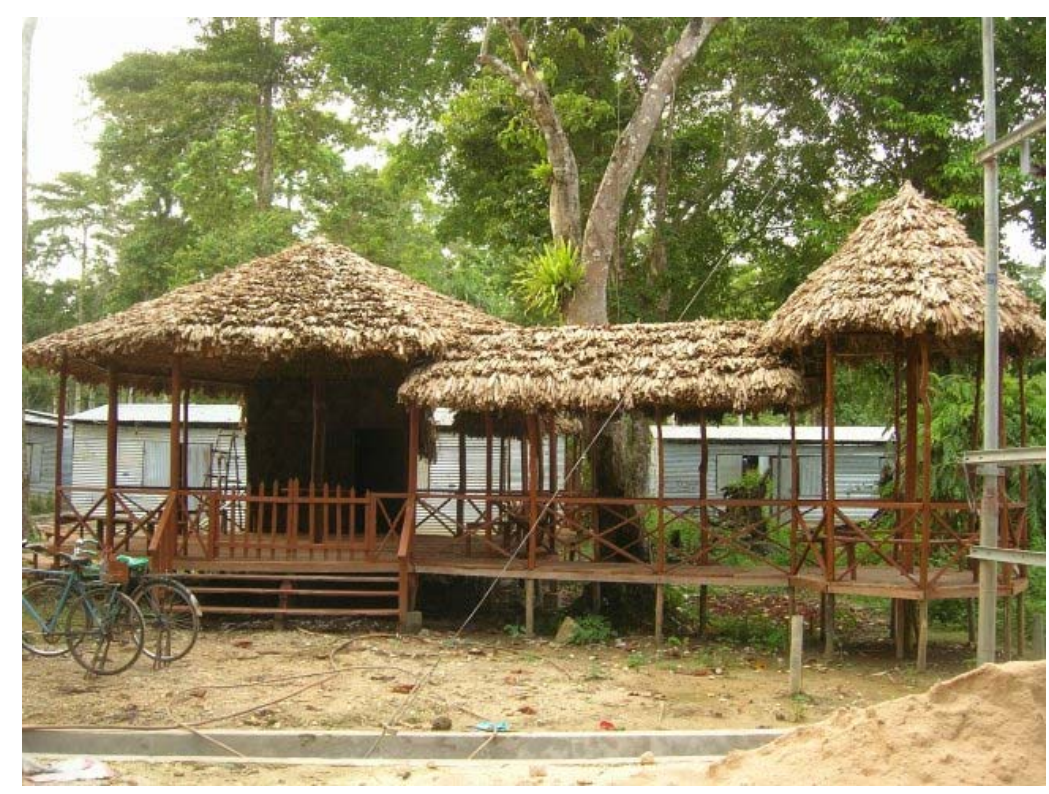

FIGURE 3

COMMUNITY CENTER IN HUTBAY, LITTLE ANDAMAN ISLAND.

Interns are required to complete individual reports documenting and critically analyzing the work completed during the internship. The reports are an invaluable opportunity for interns to reflect on their experiences and are archived by ESW-Stanford to ensure transfer of knowledge. To ensure completion of the report, the report, along with supplementary documents and relevant paperwork, must be submitted to ESW-Stanford prior to receiving the final reimbursement for living expenses during the internship.

\section{ChALLENGES TO THE MODEL}

Despite what we consider to be the unabashed success of the model, we recognize that there are several challenges. Since the design course is student led, students, faculty, and accreditation boards may perceive the class as less structured or credible than more traditional courses. Additionally, the lack of a faculty member(s) who is responsible for the course raises concerns about the long-term viability of the model. Perhaps related to these two issues is the reality that the course, while design-based, is only available for elective credit; students cannot use the course to meet the design requirements of the engineering curriculum. However, this is not unique to our model, as the report from a recent workshop on service learning in engineering found that accreditation requirements are a significant challenge to incorporating servicelearning ${ }^{31}$. While it has been pointed out that service-learning might be a more efficient method of satisfying accreditation criteria ${ }^{32}$, the burden of proof is substantial. Without greater faculty involvement, the "Design for a Sustainable World" course will likely remain an elective, and as such faces stiff competition in an already packed curriculum.

The relatively short timeframe of both the design course and the internships, limits the scope of projects that can be pursued. Additionally, by focusing on a specific project, students gain a deep understanding of sustainable design concepts directly related to the project, but the breadth of material studied is necessarily limited. To some extent, lectures, readings, and homework assignments in the design course are chosen to provide broader exposure but this has to be 
balanced against the specific technical needs of the project. Students may repeat the course as different types of projects are offered to gain breadth, but given the demands of the engineering curriculum this rarely if ever occurs.

Another significant limitation of the model is the substantial cost of the internships and the amount of fundraising effort required. Similar to other programs that link international internships with coursework (e.g., ${ }^{33}$ ) the majority of the budget is spent on travel and related expenses. The cost effectively limits both the number of projects that can be pursued and the number of participants. Additionally, the inherent unpredictability of annual fundraising efforts means that there is little assurance that ESW-Stanford will continue to be able to provide internship opportunities.

\section{VISIONS FOR THE FUTURE}

ESW-Stanford is currently working to make the "Design for a Sustainable World" course and associated projects a permanent fixture in the Stanford University curriculum. Although the flexibility of Stanford made it possible to start a student-initiated course, it is difficult to get the course institutionalized. We are attempting to get greater faculty involvement and support for the course to ensure that it can continue to be offered twice per year. Ideally, with the support of tenured faculty, the design course will be recognized as providing an alternative method of satisfying accreditation criteria.

One of the most difficult aspects of the ESW-Stanford model is finding projects and partners in a timely manner. To ensure continuity, we would like to create a backlog of projects. While our projects to date have focused on sustainable development in an international context, we are considering adding projects based in the U.S. We are particularly excited about projects on the Stanford campus or in surrounding communities that can be linked to international projects. For example, we are looking to initiate an ecological sanitation project on the Stanford campus that might serve as a prototype for future efforts in Haiti.

ESW-Stanford is continually evaluating its processes and methods in order to streamline and improve them. We are particularly focused on how best to recruit and screen applicants for the course and internships. A related issue is how to decide the appropriate composition for the course and internships, e.g. the number of undergraduates versus graduates or the distribution among majors. We are also working hard to improve the transfer of knowledge from previous to future projects and are experimenting with ways to organize and archive information and lessons-learned.

We hope to form greater linkages with the ESW Professional chapter in the San Francisco Bay area, as well as with nearby industry professionals, to collaborate on future projects and fundraising. Also, by keeping in touch with students who have graduated we will establish a network of professional alumni who can help create sustainable engineering solutions and serve as a resource for future projects.

\section{ACKNOWLEDGMENT}

We would like to express our sincere gratitude to the following organizations for their financial contributions, without which this work would not be possible: The Blume Earthquake Engineering Center (Stanford), The Center for Environmental Science and Policy (Stanford Institute for International Studies), the Department of Civil and Environmental Engineering (Stanford), The Haas Center for Public Service (Stanford), Stanford Institute for the Environment, the School of Engineering (Stanford), the Santa Clara Valley chapter of the 
California Water Environment Association, and the James Hsu Memorial Fund (Community Foundation Silicon Valley). We would like to thank Sophie Walewijk for encouraging us to write this article, Ashwin Mahalingam for reading a previous draft and providing valuable comments, Volunteers for India Development and Empowerment for helping arrange the Andaman Islands project, Sustainable Ecological and Environmental Development Society for being a wonderful project partner in the Andaman Islands, Mike Knuepfel and Robert Bearman for photos used in this article, and the officers and members of ESW-Stanford for their general support and encouragement.

\section{REFERENCES}

${ }^{1}$ United Nations, General Assembly, 55th Session, United Nations Millennium Declaration (A/RES/55/2), 18 September 2000. Also available online at http://www.un.org/millennium/declaration/ares552e.pdf.

${ }^{2}$ United Nations, United Nations Conference on Environment and Development, Agenda 21 (93.I.11), April 1993. Also available online at http://www.un.org/esa/sustdev/documents/agenda21/english/agenda21toc.htm.

${ }^{3}$ United Nations, World Summit on Sustainable Development, Report of the World Summit on Sustainable Development (A/CONF.199/20), January 2003. Also available online at http://www.johannesburgsummit.org/html/documents/documents.html.

${ }^{4}$ Adisa Azapagic, Slobodan Perdan, and David Shallcross, "How much do engineering students know about sustainable development? The findings of an international survey and possible implications for the engineering curriculum,” European Journal of Engineering Education 30, no. 1 (2005), 1-19.

${ }^{5}$ Azapagic, "How much do engineering students know about sustainable development? The findings of an international survey and possible implications for the engineering curriculum,” 1-19.

${ }^{6}$ Forum for the Future, The engineer of the $21^{\text {st }}$ century inquiry: engineers for sustainability (London: Forum for the Future, 2000). Also available online at http://www.forumforthefuture.org.uk/uploadstore/Engineers_for_Sustainability.pdf

${ }^{7}$ Forum for the Future, The engineer of the $21^{\text {st }}$ century inquiry: change challenges for sustainability (London: Forum for the Future, 2003). Also available online at http://www.forumforthefuture.org.uk/ChangeChallengesforSustainability_pdf_media_public.aspx

${ }^{8}$ Mary R. Anderson-Rowland,. "Service Learning with Student Organizations." (paper presented at 25th Annual Conference on Frontiers in Education, Atlanta, GA, USA, Nov 1-4 1995), 777-779.

${ }^{9}$ Hazem Said, "Improving Students Retention by Engaging Them in Real Life Experiences." (paper presented at ASEE Annual Conference, Salt Lake City, UT, USA, June 20-23, 2004), 7021-7025.

${ }^{10}$ M.S. Pritchard, "Service-Learning and Engineering Ethics," Science and Engineering Ethics 6, no. 3 (2000), 41322.

${ }^{11}$ Mark Horenstein, and Michael Ruane. "Teaching Social Awareness through the Senior Capstone Design Experience," (paper presented at the 32nd Annual Conference on Frontiers in Education, Boston, MA, USA, Nov 69 2002), S3D/7-12.

${ }^{12}$ Randall J. Brouwer, "Integrating Service Learning into a First-Year Engineering Course," (paper presented at the 29th Annual Conference on Frontiers in Education, San Juan, Puerto Rico, Nov 10-13 1999), 12a6-17.

${ }^{13}$ Susan M. Lord, "Service-Learning in Introduction to Engineering at the University of San Diego: First Lessons," (paper presented at the 29th Annual Conference on Frontiers in Education, San Juan, Puerto Rico, Nov 10- 13 1999), 13b6-21.

${ }^{14}$ Rosalyn S. Hobson, "Service-Learning as an Educational Tool in an Introduction to Engineering Course," (paper presented at the ASEE Annual Conference, St. Louis, MO, USA, Jun 18-21 2000), 5167-5176.

${ }^{15}$ William Oakes and Michael Thompson, "Integration of Service Learning into a Freshman Engineering Course," (paper presented at the ASEE Annual Conference, Salt Lake City, UT, United States, Jun 20-23 2004), 7991-8017.

${ }^{16}$ Paul Johnson and D.H. Zitomer, "International Service Learning in Environmental Engineering," (paper presented at the World Water and Environmental Resources Congress, Philadelphia, PA, USA, Jun 23-26 2003), 1917-1924. 
${ }^{17}$ William Oakes, Edward J. Coyle, Richard Fortek, Jeffery Gray, Leah H. Jamieson, Jennifer Watia, and Ronald Wukasch, "Epics: Experiencing Engineering Design through Community Service Projects," (paper presented at the ASEE Annual Conference, St. Louis, MO, USA, Jun 18-21 2000), 2611-2622.

${ }^{18}$ M.S. Talbert, Farnkhopf, S.A. Jones, and R. Houghtalen, "Combining Service Learning with Graduate Education, " Journal of Professional Issues in Engineering Education and Practice 129, no. 4 (2003): 211-15

${ }^{19}$ Christopher W.Swan, Charline S. Han, and James F. Limbrunner, "Service Learning on an International Scale: The Experiences of Tufts University," (paper presented at the ASEE Annual Conference, Portland, OR, USA, Jun 12-15 2005), 12613-12619.

${ }^{20}$ David Vader, Carl A. Erikson, and John W. Eby, "Cross-Cultural Service Learning for Responsible Engineering Graduates,." (paper presented at the ASEE Annual Conference, Charlotte, NC, USA, Jun 20-23 1999), 1427-1436.

${ }^{21}$ Kenneth M. Bryden, Kevin P. Hallinan, and Margaret F. Pinnell, "A Different Path to Internationalization of Engineering Education," (paper presented at the 32nd Annual Conference on Frontiers in Education, Boston, MA, USA, Nov 6-9 2002), S4B/2.

${ }^{22}$ Matthew G. Green, Kristin L. Wood, Frank T. Duda, Nolan Van Gaalen, Steven H. Vanderleest, and Carl Erikson, "Service-Learning Approaches to International Humanitarian Design Projects: A Model Based on Experiences of Faith-Based Institutions," (paper presented at the ASEE Annual Conference, Salt Lake City, UT, USA, Jun 20-23 2004), 12533-12554.

${ }^{23}$ Richard Vaz, "Reflections on Fifteen Years of Service-Learning Projects in Thailand," (paper presented at the ASEE Annual Conference, Portland, OR, USA, Jun 12-15 2005), 12139-12148.

${ }^{24}$ Angela R. Bielefeldt, R. Scott Summers, Bernard Amadei, Margaret Pinnell, William Moeller, Robyn Sandekian, and Jay Shah, "Creating an Engineering for Developing Communities (Edc) Emphasis in Environmental

Engineering," (paper presented at the ASEE Annual Conference, Portland, OR, USA, Jun 12-15 2005), 2437-2450.

${ }^{25}$ Robyn,Sandekian, Bernard Amadei, and Margaret Pinnell. "A Summary of the Workshop on Integrating Appropriate-Sustainable Technology and Service-Learning in Engineering Education," (paper presented at the ASEE Annual Conference, Portland, OR, USA 2005).

${ }^{26}$ Data are the results of a search of the Engineering Index ${ }^{\circledR}$ using the terms "service-learning” and "engineering."

${ }^{27} \mathrm{http}: / /$ esustainableworld.org/about/

${ }^{28}$ Oakes, "Epics: Experiencing Engineering Design through Community Service Projects," 2612.

${ }^{29}$ Green, "Service-Learning Approaches to International Humanitarian Design Projects: A Model Based on Experiences of Faith-Based Institutions," 12549.

${ }^{30}$ Oakes, "Epics: Experiencing Engineering Design through Community Service Projects," 2612.

${ }^{31}$ Sandekian, "A Summary of the Workshop on Integrating Appropriate-Sustainable Technology and ServiceLearning in Engineering Education."

32 John Duffy, Edmund Tsang, and Susan Lord. "Service-Learning in Engineering: What, Why, and How?," (paper presented at the ASEE Annual Conference, St. Louis, MO, USA, Jun 18-21 2000), 5183-5191.

${ }^{33}$ Carl W Eger III and Margaret F. Pinnell, "Appropriate Technology and Technical Service in Developing Countries (ETHOS) Elective Course," (paper presented at the ASEE Annual Conference, Portland, OR, USA 2005), $675-684$ 